\title{
Obesity, Quality of Sleep and Anxiety in Saudi Arabia
}

\author{
Noara Alhusseini'*, Basant Elaasser², Bushra Alshaar², Shahd Alyousof², Susan Boukhet'², Aamir Omair ${ }^{3}$
}

\author{
'Director of the Master of Public Health Program, Senior Lecturer, College of Medicine, Alfaisal University, Riyadh, Saudi Arabia. \\ ${ }^{2}$ College of Medicine, Alfaisal University, Riyadh, Saudi Arabia. \\ ${ }^{3}$ Research Unit, College of Medicine, King Saud bin Abdulaziz University for Health Sciences, Riyadh, Saudi Arabia. \\ *Correspondence to: Dr. Noara Alhusseini (E-mail: nalhusseini@alfaisal.edu) \\ (Submitted: 18 April 2021 - Revised version received: 05 May 2021 - Accepted:22 May 2021 - Published online: 26 August 2021)
}

\begin{abstract}
Introduction There is an inter-relationship between sleeping hours, anxiety, and metabolic effects that predispose the body to weight changes. The aim is to determine an association between obesity levels, quality of sleep, and anxiety among the Saudi population.

Methods A cross-sectional study was used by distributing an online questionnaire via social media channels to the Saudi population. We used the body mass index (BMI) to assess body fat, the Pittsburg Sleep Quality Index (PSQI), and Generalized Anxiety Disorder - 7 (GAD-7). Chi-square tests and logistic regression were used to test associations with a $P$-value of less than 0.05 .

Results We received a total of 1123 respondents and the majority (61\%) were obese and overweight. According to the GAD-7 score, $17 \%$ had severe anxiety; the PSQI score was $8.42 \pm 3.45$, indicating overall poor sleep quality. Underweight respondents had higher moderate $(25 \%)$ and severe (26\%) anxiety as compared to those with normal or higher BMI $(14 \%-18 \%)(P=0.002)$. PSQI scores were higher for obese $(8.9 \pm 3.6)$ and overweight $(8.6 \pm 3.4)$ respondents as compared to underweight $(7.5 \pm 3.0)(P=0.001)$. Persons with severe $(10.4 \pm 3.6)$ or moderate $(9.7 \pm 3.7)$ anxiety had higher PSQI scores as compared to those with minimal anxiety $(6.8 \pm 2.7)(P<0.001)$.

Conclusion There is a relationship between obesity, sleep, and anxiety. Overweight and obesity were significantly associated with anxiety and poor sleep quality in Saudi Arabia.

Keywords Obesity, overweight, quality of sleep, anxiety, Saudi population
\end{abstract}

\section{Introduction}

Obesity is defined by excessive body fat in the human body. It is a chronic, multifactorial disease that causes both psychological and physical stress. It can occur at any stage in life and can develop in children and adults. ${ }^{1}$ The etiologies of obesity include iatrogenic, dietary, neuroendocrine, social, behavioral, lifestyle, and genetic causes. ${ }^{1}$ Obesity can lead to cardiovascular diseases, type II diabetes, osteoarthritis, cancer, and overall decreased life expectancy. ${ }^{2}$ The Body Mass Index (BMI) is mostly used for the determination of the severity of obesity. The higher the BMI, the higher the chance of morbidity and mortality. ${ }^{3}$

As technology has moved forward and people moved less, the rate of obesity has nearly doubled worldwide and is now considered a pandemic. ${ }^{4}$ The rate of obesity in the Kingdom of Saudi Arabia (KSA) has doubled in the past ten years as $66 \%$ of males are overweight and $28 \%$ obese, whereas $71 \%$ of females are overweight and $44 \%$ are obese. ${ }^{5,6}$ Lifestyle factors contributing to unhealthy eating habits in KSA include frequent consumption of sugary beverages and calorie-dense meals, lack of publicly accessible walkways, lack of physical education in schools, and increased screening time. ${ }^{7}$ In addition, the desert climate discourages outdoor activities and encourages late rising and resting, including insufficient or excessive sleep. ${ }^{8}$

Sleep is an easily reversible state of unconsciousness with reduced metabolic and motor activities. ${ }^{9}$ Sleep is essential for waking cognition, i.e., attention, alertness, vigilance, clear thinking, and memory consolidation, and emotional regulation. ${ }^{10}$ There is variability in the sleep duration needed by each individual but the American Academy of Sleep Medicine (AASM) and Sleep Research Society (SRS) recommends seven hours or more of sleep per night for adults. ${ }^{11}$ Acute sleep deprivation mainly causes cognitive impairment where individuals take a long time and find more difficulty performing daily tasks. Other effects include changes in mood, judgment, and respiratory physiology. ${ }^{12}$ On the other hand, chronic sleep deprivation usually results in more-subtle effects where the individual is more prone to accidents, cardiovascular morbidity, immunosuppression, obesity, and an overall decreased quality of life and lifespan. ${ }^{13}$ Recent scientific literature revealed a link between sleeping hours and metabolic effects that predispose to weight changes, also, an association between increased body mass index (BMI) and short sleeping hours. ${ }^{14}$

Anxiety disorders are common mental health conditions. ${ }^{15}$ The level of anxiousness people experience in anxiety disorders is over-proportionate to the situation, causing unpleasant emotions and/or physical changes, like disruption of blood pressure level and gastrointestinal distress. ${ }^{16,17}$ Anxiety disorders interfere with day to day tasks through repetitive attacks of abrupt feelings of persistent, intense anxiety, fear, terror, and high discomfort. ${ }^{15-17}$ Anxiety attacks are longlasting and difficult to control. ${ }^{15-17}$

Anxiety disorders are subdivided into various types, like, generalized anxiety disorder (GAD), panic disorder, and phobiarelated disorders. ${ }^{16}$ Generalized Anxiety Disorder causes sleeping problems, and new research suggests sleep deprivation can cause an anxiety disorder. ${ }^{16,17}$ Research also suggests sleep disruption is present in nearly all psychiatric disorders. ${ }^{16,17}$ Moreover, people with chronic insomnia are at high risk of developing anxiety disorders. ${ }^{17}$ Recent scholars demonstrate a relationship between anxiety disorders and obesity like panic attacks and phobias, but the association between GAD and obesity is still under research; there are studies that suggest an association, and others contradict the relationship..$^{18}$ The relation of this array of irregular sleep duration, anxiety, and obesity in KSA is not well studied and may benefit from further research.

This study aimed to find an association between obesity levels, quality of sleep, and anxiety among the Saudi population. There are limited peer-reviewed studies that target obesity levels in relation to quality of sleep and anxiety level. This 
study is novel as it adds new information to the current literature among the Saudi population.

\section{Methods}

This was a cross-sectional study design. The study population consisted of adults in Saudi Arabia. The inclusion criteria were 18 years old or above, Saudis and non-Saudis. An online questionnaire was distributed via social media platforms including WhatsApp, Twitter, Facebook, and LinkedIn. The estimated annual population of Saudi Arabia in 2020 is around 34.8 million. The sample size was 384, with a $95 \%$ confidence level and $5 \%$ margin of error for an expected 50\% prevalence for the outcome variable.

The online questionnaire was taken from previously validated studies ${ }^{19,20}$ it was modified to fit the objectives of the study. It included demographic questions, height, weight, quality of sleep assessment, and assessing anxiety. The questionnaire was distributed in both English and Arabic languages. Face and content validity were achieved by a public health specialist and a translator. The names of the respondents were not collected to ensure anonymity and confidentiality. Filling the survey was construed as consent. Participation in the study was voluntary and respondents were able to withdraw at any time. Approval from the Institutional Review Board (IRB) at Alfaisal University was achieved IRB-20062.

The body mass index (BMI) was used for assessing body fat. It is calculated by dividing an individual's weight in kilograms by their height in meters squared. The result of this calculation is the individual's BMI. BMI was used to categorize a person as underweight, normal weight, overweight, or obese. The classifications are severely underweight BMI less than $16.5 \mathrm{~kg} / \mathrm{m}^{2}$, underweight - BMI under $18.5 \mathrm{~kg} / \mathrm{m}^{2}$, normal weight - BMI greater than or equal to 18.5 to $24.9 \mathrm{~kg} / \mathrm{m}^{2}$, overweight - BMI greater than or equal to 25 to $29.9 \mathrm{~kg} / \mathrm{m}^{2}$, obesity class I - BMI between 30 to $34.9 \mathrm{~kg} / \mathrm{m}^{2}$, obesity class II -BMI between 35 to $39.9 \mathrm{~kg} / \mathrm{m}^{2}$, obesity class III -BMI $40 \mathrm{~kg} / \mathrm{m}^{2}{ }^{21}$

For assessing the quality of sleep, the Pittsburg Sleep Quality Index (PSQI) was used. It is a screening measure consisting of ten questions used to differentiate "good" from "poor" sleepers. ${ }^{20}$ The PSQI is of 7 components, with each component having four different responses, each scored as $0,1,2,3$, respectively. Component 1 (Q9) was subjective sleep quality-labeled as very good, fairly good, fairly bad, or very bad scored at $0,1,2$, 3 , respectively. Component $2(\mathrm{Q} 2,5 \mathrm{a})$ was sleep latency, which was split into two parts. Part one was how long it takes to fall asleep labeled as $<15$ minutes, 16-30 minutes, 31-60 minutes, or $>60$ minutes scored at $0,1,2,3$, respectively. Part two was being unable to sleep within 30 minutes labeled as not during past month, less than once a week, once or twice a week, three or more times a week scored at $0,1,2,3$ respectively. The sum of scores from both parts were labeled as [0], [1 or 2], [3 or 4], or [5 or 6] scored at $0,1,2,3$, respectively.

Component 3 (Q4) was sleep duration labeled as $>7$ hours, 6-7 hours, 5-6 hours, or $<5$ hours scored at $0,1,2,3$, respectively. Component $4(\mathrm{Q} 1,3,4)$ was sleep efficiency calculated by sleep efficiency $=$ (\# hours slept/\# hours in bed) $\mathrm{x} 100 \%$ where \# hours slept was from question 4 and \# hours in bed was calculated from responses to questions 1 and 3 in the survey. The result was labelled as $>85 \%, 75-84 \%, 65-74 \%$, or $<65 \%$ scored at $0,1,2,3$ respectively. Component 5 (Q5b-j) was sleep disturbance labeled as not during the past month, less than once a week, once or twice a week, three or more times a week scored at $0,1,2,3$, respectively. The sum of all scores in this component was labeled as $0,1-9,10-18$, or 19-27 scored at $0,1,2,3$, respectively.

Component 6 (Q6) was use of sleep medication labeled as not during the past month, less than once a week, once or twice a week, or three or more times a week scored at $0,1,2,3$, respectively. Component $7(\mathrm{Q} 7,8)$ was daytime dysfunction, which split into two parts. Part one was trouble staying awake labeled as not during the past month, less than once a week, once or twice a week, or three or more times a week scored at $0,1,2,3$, respectively. Part two was trouble keeping up enthusiasm labeled as no problem at all, only a very slight problem, somewhat of a problem, or a very big problem scored at $0,1,2$, 3 respectively. The sum of scores from both parts were labeled as [0], [ 1 or 2], [3 or 4], or [5 or 6] scored at $0,1,2,3$, respectively. With all components of PSQI complete, the Global PSQI Score was the sum of all seven individual component scores. The answers were then scored using an established guideline. A global PSQI score of more than five indicated poor sleeping with a diagnostic sensitivity of $89.6 \%$ and specificity of $86.5 \%$ (kappa $=0.75, p \leq 0.001){ }^{20}$

Generalized Anxiety Disorder - 7 (GAD-7) is a validated and reliable assessment tool in GAD screening; it is used by the Saudi Ministry of Health in primary health care centers. ${ }^{19}$ GAD-7 contained seven questions that measure anxiety severity where each item asked the individual to rate symptoms severity over the past two weeks. The severity of symptoms were labeled as not at all, several days, more than half the days, or nearly every day. Scores were given to each label respectively: $0,1,2,3$. All scores were added together, and the total was then classified as follows. Total scores of $0-4$ indicated minimal anxiety, 5-9 indicated mild, probably subclinical anxiety, and monitoring is recommended. Total scores of 10-14 indicated moderate, possibly clinically significant anxiety, and further evaluation and treatment (if needed) are recommended. Total scores of 15-21 indicated severe, probably clinically significant anxiety, and treatment is probably warranted. ${ }^{19}$

The data was entered and analyzed using SPSS v23. The categorical data were presented as frequencies and percentages, while the numerical data were presented as mean \pm standard deviation. The Chi-Square test was used to determine the association of GAD-7 categories with BMI groups and exercise frequency. ANOVA was used to assess the association of PSQI scores with the above two variables and GAD-7 classes. A $p$-value $<0.05$ was considered to show a statistically significant association for all the statistical tests.

The authors obtained ethical approval from Alfaisal University Institutional Review Board (IRB). The authors abided by the Saudi National Committee of Bioethics (NCBE) and the Research Policies \& Procedures of Alfaisal University. No identifying data was collected to ensure anonymity and confidentiality. The investigators only had access to the survey responses.

\section{Results}

There were a total of 1123 Saudi and non-Saudi respondents to the survey and their demographic characteristics are shown in Table 1. The highest proportion were in the age group 18-29 years for both Saudis (42\%) and non-Saudi (41\%) respondents $(P=0.63)$. There was a higher proportion of females among the Saudi $(76 \%)$ as compared to the non-Saudi (66\%) respondents 
$(P<0.001)$. A greater proportion of non-Saudis $(59 \%)$ were married as compared to the Saudi (53\%) respondents $(P=0.02)$. A greater proportion of Saudis (46\%) were employed as compared to the non-Saudi (39\%) respondents $(P=0.03)$; there was a higher proportion of the non-Saudis (47\%) who did not have a monthly income as compared to the Saudi (32\%) respondents $(P<0.001)$. There was a greater proportion of

\begin{tabular}{|c|c|c|c|c|c|c|}
\hline & & \multicolumn{4}{|c|}{ Nationality } & \multirow{3}{*}{$P$-value } \\
\hline & & \multicolumn{2}{|c|}{ Saudi $(n=544)$} & \multicolumn{2}{|c|}{ Non-Saudi ( $n=579)$} & \\
\hline & & $n$ & $\%$ & $n$ & $\%$ & \\
\hline \multirow{3}{*}{ Age } & $18-29$ yrs & 231 & $42 \%$ & 236 & $41 \%$ & \multirow{3}{*}{0.63} \\
\hline & $30-44$ yrs & 206 & $38 \%$ & 216 & $37 \%$ & \\
\hline & $45+y r s$ & 107 & $20 \%$ & 127 & $22 \%$ & \\
\hline \multirow{2}{*}{ Gender } & Female & 413 & $76 \%$ & 383 & $66 \%$ & \multirow{2}{*}{$<0.001$} \\
\hline & Male & 131 & $24 \%$ & 196 & $34 \%$ & \\
\hline \multirow{3}{*}{ Marital status (3 groups) } & Single & 227 & $42 \%$ & 222 & $38 \%$ & \multirow{3}{*}{0.02} \\
\hline & Married & 290 & $53 \%$ & 343 & $59 \%$ & \\
\hline & Divorced/Widowed & 27 & $5 \%$ & 14 & $2 \%$ & \\
\hline \multirow{2}{*}{ Employment Status } & Yes & 250 & $46 \%$ & 228 & $39 \%$ & \multirow{2}{*}{0.03} \\
\hline & No & 294 & $54 \%$ & 351 & $61 \%$ & \\
\hline \multirow{5}{*}{ Monthly Income } & $<10,000$ SR & 104 & $19 \%$ & 73 & $13 \%$ & \multirow{5}{*}{$<0.001$} \\
\hline & 10,000 to $<20,000 S R$ & 100 & $18 \%$ & 46 & $8 \%$ & \\
\hline & $20,000+S R$ & 62 & $11 \%$ & 58 & $10 \%$ & \\
\hline & I prefer not to answer & 104 & $19 \%$ & 131 & $23 \%$ & \\
\hline & I do not have a monthly income & 174 & $32 \%$ & 271 & $47 \%$ & \\
\hline \multirow{3}{*}{ Highest Degree } & High school, Diploma, or less & 230 & $42 \%$ & 193 & $33 \%$ & \multirow{3}{*}{$<0.001$} \\
\hline & Bachelors degree & 244 & $45 \%$ & 246 & $42 \%$ & \\
\hline & Postgraduate degree & 70 & $13 \%$ & 140 & $24 \%$ & \\
\hline
\end{tabular}

Table 2. BMI categories and Exercise frequencies of the participants and outcome from GAD-7 and PSQI questionnaires $(\boldsymbol{N}=\mathbf{1 1 2 3})$

\begin{tabular}{|c|c|c|c|c|c|c|}
\hline & & \multicolumn{4}{|c|}{ Nationality } & \multirow{3}{*}{$P$-value } \\
\hline & & \multicolumn{2}{|c|}{ Saudi $(n=544)$} & \multicolumn{2}{|c|}{ Non-Saudi $(n=579)$} & \\
\hline & & $n$ & $\%$ & $n$ & $\%$ & \\
\hline \multirow{4}{*}{$\mathrm{BMI}\left(\mathrm{kg} / \mathrm{m}^{2}\right)$} & Underweight (<18.5) & 28 & $5 \%$ & 25 & $4 \%$ & \multirow{4}{*}{0.87} \\
\hline & Normal weight $(18.5$ to $<25)$ & 191 & $35 \%$ & 197 & $34 \%$ & \\
\hline & Overweight $(25$ to $<30)$ & 170 & $31 \%$ & 187 & $32 \%$ & \\
\hline & Obese (30+) & 153 & $28 \%$ & 169 & $29 \%$ & \\
\hline \multirow{4}{*}{ Exercise } & None & 122 & $22 \%$ & 136 & $23 \%$ & \multirow{4}{*}{0.89} \\
\hline & $1-4$ times per month & 209 & $38 \%$ & 224 & $39 \%$ & \\
\hline & 2-3 times per week & 158 & $29 \%$ & 168 & $29 \%$ & \\
\hline & 4-6 times per week & 55 & $10 \%$ & 51 & $9 \%$ & \\
\hline \multirow{4}{*}{ GAD7 } & Minimal anxiety & 187 & $34 \%$ & 202 & $35 \%$ & \multirow{4}{*}{0.03} \\
\hline & Mild anxiety & 170 & $31 \%$ & 156 & $27 \%$ & \\
\hline & Moderate anxiety & 110 & $20 \%$ & 103 & $18 \%$ & \\
\hline & Severe anxiety & 77 & $14 \%$ & 118 & $20 \%$ & \\
\hline PSQI score & Mean $\pm s d$ & \multicolumn{2}{|c|}{$8.7 \pm 3.5$} & \multicolumn{2}{|c|}{$8.1 \pm 3.3$} & 0.005 \\
\hline
\end{tabular}


groups with regards to BMI $(P=0.87)$ and exercise frequency $(P=0.89)$. The proportion of respondents who were normal weight was 35\% in Saudi and 34\% in Non-Saudi respondents, while overweight/obese were $59 \%$ and $61 \%$ respectively for the two groups. There were $60 \%$ Saudis and $62 \%$ non-Saudi respondents who reported no exercise/1-4 times per month, and 29\% in both groups reported exercising 2-3 times per week. There was a significant difference for both the GAD-7 and PSQI scores between the Saudis and Non-Saudis. The Non-Saudi respondents had a higher proportion $(20 \%)$ of severe anxiety as compared to $14 \%$ in the Saudi respondents. The PSQI score was higher for the Saudis $(8.7 \pm 3.5)$ as compared to the Non-Saudi $(8.1 \pm 3.3)$ respondents $(P=0.005)$.

Table 3 shows that in the Saudi respondents, there was a significant association $(P<0.001)$ between the BMI groups and the GAD-7 categories. It was found that the 'Normal weight' group had the highest proportion $(46 \%)$ of minimal anxiety as compared to $20 \%$ in the obese group. The obese group was found to have the highest proportion of severe (18\%) anxiety as compared to the other three BMI groups, while the underweight group had the highest proportion of candidates with moderate anxiety (32\%). There was no significant association found between BMI group and GAD-7 for the Non-Saudi respondents $(P=0.28)$.

Table 4 shows an opposite result where there was no significant association between GAD-7 categories and frequency of exercise for the Saudi respondents $(P=0.36)$. But there was a significant association of GAD-7 with exercise frequency for the non-Saudi group $(P=0.02)$. The proportion of minimal anxiety was higher in respondents who exercised frequently

\begin{tabular}{|c|c|c|c|c|c|c|c|}
\hline & \multirow[b]{2}{*}{ BMI kg/m² } & \multirow[b]{2}{*}{$n$} & \multicolumn{4}{|c|}{ GAD7 } & \multirow[b]{2}{*}{$P$-value } \\
\hline & & & $\begin{array}{c}\text { Minimal } \\
\text { anxiety }\end{array}$ & $\begin{array}{c}\text { Mild } \\
\text { anxiety }\end{array}$ & $\begin{array}{c}\text { Moderate } \\
\text { anxiety }\end{array}$ & $\begin{array}{c}\text { Severe } \\
\text { anxiety }\end{array}$ & \\
\hline \multirow{8}{*}{ Saudi $(n=544)$} & Underweight $(<18.5)$ & 28 & 10 & 5 & 9 & 4 & \multirow{8}{*}{$<0.001$} \\
\hline & & & $36 \%$ & $18 \%$ & $32 \%$ & $14 \%$ & \\
\hline & Normal weight (18.5 to <25) & 191 & 87 & 46 & 35 & 23 & \\
\hline & \multirow{3}{*}{ Overweight (25 to <30) } & \multirow{3}{*}{170} & $46 \%$ & $24 \%$ & $18 \%$ & $12 \%$ & \\
\hline & & & 60 & 52 & 37 & 21 & \\
\hline & & & $35 \%$ & $31 \%$ & $22 \%$ & $12 \%$ & \\
\hline & \multirow[t]{2}{*}{ Obese (30+) } & \multirow[t]{2}{*}{153} & 30 & 67 & 29 & 27 & \\
\hline & & & $20 \%$ & $44 \%$ & $19 \%$ & $18 \%$ & \\
\hline \multirow{8}{*}{$\begin{array}{l}\text { Non-Saudi } \\
(n=579)\end{array}$} & \multirow[t]{2}{*}{ Underweight $(<18.5)$} & \multirow[t]{2}{*}{25} & 7 & 4 & 4 & 10 & \multirow{8}{*}{0.28} \\
\hline & & & $28 \%$ & $16 \%$ & $16 \%$ & $40 \%$ & \\
\hline & Normal weight (18.5 to <25) & 197 & 72 & 53 & 40 & 32 & \\
\hline & \multirow{3}{*}{ Overweight (25 to <30) } & \multirow{3}{*}{187} & $37 \%$ & $27 \%$ & $20 \%$ & $16 \%$ & \\
\hline & & & 64 & 48 & 31 & 44 & \\
\hline & & & $34 \%$ & $26 \%$ & $17 \%$ & $24 \%$ & \\
\hline & \multirow[t]{2}{*}{ Obese (30t) } & \multirow[t]{2}{*}{169} & 58 & 51 & 28 & 32 & \\
\hline & & & $34 \%$ & $30 \%$ & $17 \%$ & $19 \%$ & \\
\hline
\end{tabular}

\begin{tabular}{|c|c|c|c|c|c|c|c|}
\hline & \multirow[b]{2}{*}{ Exercise } & \multirow[b]{2}{*}{$n$} & \multicolumn{4}{|c|}{ GAD7 } & \multirow[b]{2}{*}{$P$-value } \\
\hline & & & $\begin{array}{l}\text { Minimal } \\
\text { anxiety }\end{array}$ & $\begin{array}{c}\text { Mild } \\
\text { anxiety }\end{array}$ & $\begin{array}{c}\text { Moderate } \\
\text { anxiety }\end{array}$ & $\begin{array}{l}\text { Severe } \\
\text { anxiety }\end{array}$ & \\
\hline \multirow{8}{*}{ Saudi } & None & 122 & 40 & 39 & 27 & 16 & \multirow{8}{*}{0.36} \\
\hline & & & $33 \%$ & $32 \%$ & $22 \%$ & $13 \%$ & \\
\hline & 1-4 times per month & 209 & 63 & 67 & 49 & 30 & \\
\hline & & & $30 \%$ & $32 \%$ & $23 \%$ & $14 \%$ & \\
\hline & \multirow[t]{2}{*}{ 2-3 times per week } & \multirow[t]{2}{*}{158} & 62 & 50 & 27 & 19 & \\
\hline & & & $39 \%$ & $32 \%$ & $17 \%$ & $12 \%$ & \\
\hline & \multirow[t]{2}{*}{ 4-6 times per week } & \multirow[t]{2}{*}{55} & 22 & 14 & 7 & 12 & \\
\hline & & & $40 \%$ & $25 \%$ & $13 \%$ & $22 \%$ & \\
\hline
\end{tabular}




\begin{tabular}{|c|c|c|c|c|c|c|c|}
\hline & \multirow[b]{2}{*}{ Exercise } & \multirow[b]{2}{*}{$n$} & \multicolumn{4}{|c|}{ GAD7 } & \multirow[b]{2}{*}{$P$-value } \\
\hline & & & $\begin{array}{l}\text { Minimal } \\
\text { anxiety }\end{array}$ & $\begin{array}{c}\text { Mild } \\
\text { anxiety }\end{array}$ & $\begin{array}{c}\text { Moderate } \\
\text { anxiety }\end{array}$ & $\begin{array}{l}\text { Severe } \\
\text { anxiety }\end{array}$ & \\
\hline \multirow{8}{*}{ Non-Saudi } & None & 136 & 43 & 39 & 19 & 35 & \multirow{8}{*}{0.02} \\
\hline & & & $32 \%$ & $29 \%$ & $14 \%$ & $26 \%$ & \\
\hline & 1-4 times per month & 224 & 64 & 72 & 45 & 43 & \\
\hline & & & $29 \%$ & $32 \%$ & $20 \%$ & $19 \%$ & \\
\hline & \multirow[t]{2}{*}{ 2-3 times per week } & 168 & 70 & 37 & 32 & 29 & \\
\hline & & & $42 \%$ & $22 \%$ & $19 \%$ & $17 \%$ & \\
\hline & \multirow[t]{2}{*}{ 4-6 times per week } & 51 & 25 & 8 & 7 & 11 & \\
\hline & & & $49 \%$ & $16 \%$ & $14 \%$ & $22 \%$ & \\
\hline
\end{tabular}

\begin{tabular}{|c|c|c|c|c|c|}
\hline & & \multicolumn{2}{|l|}{ Saudi $(n=540)$} & Non-Saudi $(n=578)$ & \multirow{2}{*}{$P$-value } \\
\hline & & Mean \pm SD & $p$-value & Mean \pm SD & \\
\hline \multirow{4}{*}{$\mathrm{BMI}\left(\mathrm{kg} / \mathrm{m}^{2}\right)$} & Underweight (<18.5) & $8.5 \pm 3.0$ & \multirow{4}{*}{0.12} & $6.4 \pm 2.5$ & \multirow{4}{*}{0.001} \\
\hline & Normal weight $(18.5$ to $<25)$ & $8.2 \pm 3.6$ & & $7.8 \pm 3.2$ & \\
\hline & Overweight (25 to <30) & $9.0 \pm 3.4$ & & $8.2 \pm 3.3$ & \\
\hline & Obese $(30+)$ & $9.0 \pm 3.6$ & & $8.8 \pm 3.5$ & \\
\hline \multirow{4}{*}{ Exercise } & None & $8.9 \pm 4.0$ & \multirow{4}{*}{0.34} & $8.2 \pm 3.5$ & \multirow{4}{*}{0.03} \\
\hline & 1-4 times per month & $8.8 \pm 3.4$ & & $8.5 \pm 3.2$ & \\
\hline & 2-3 times per week & $8.3 \pm 3.5$ & & $8.1 \pm 3.4$ & \\
\hline & 4-6 times per week & $9.3 \pm 2.9$ & & $6.9 \pm 3.1$ & \\
\hline \multirow{4}{*}{ GAD7 } & Minimal anxiety & $7.2 \pm 2.9$ & \multirow{4}{*}{$<0.001$} & $6.5 \pm 2.6$ & \multirow{4}{*}{$<0.001$} \\
\hline & Mild anxiety & $8.7 \pm 3.2$ & & $7.9 \pm 2.7$ & \\
\hline & Moderate anxiety & $9.5 \pm 3.6$ & & $9.9 \pm 3.8$ & \\
\hline & Severe anxiety & $11.3 \pm 3.8$ & & $9.7 \pm 3.4$ & \\
\hline
\end{tabular}

i.e., 2-3 times per week (42\%) or 4-6 times per week (49\%) as compared to those who did no exercise $(32 \%)$ or only $1-4$ times per month (29\%). The respondents who did not exercise or exercised less than four times a month had a higher proportion of mild anxiety ( $29 \%$ to $32 \%$ ) as compared to those who exercised 2-3 times per week (22\%) and 4-6 times per week (16\%). For severe anxiety, the highest proportion (26\%) was found in the group who did no exercise as compared to those who exercise $2-3$ times per week (17\%).

Table 5 shows the association between BMI, Exercise, and GAD-7 groups with the scores on the PSQI questionnaire in Saudis and non-Saudis. In the Saudi group, the BMI $(P=0.12)$ and frequency of exercise $(P=0.34)$ showed no significant association with the PSQI scores. However, there was a significant association between these two categories and the PSQI scores in the non-Saudi group. It was found that the PSQI scores were higher for respondents who were obese $(8.2 \pm 3.3)$ or overweight $(8.8 \pm 3.5)$ as compared to the underweight group $(6.4 \pm 2.5)$ $(P=0.001)$. Non-Saudi responders who exercised $4-6$ times per week had a significantly lower PSQI score $(6.9 \pm 3.1)$ as compared to the those who did no exercise $(8.2 \pm 3.5)$ or $1-4$ times per month $(8.5 \pm 3.2)(P=0.03)$. A significant association
( $P<0.001)$ was found in both the Saudi and the non-Saudi group for the PSQI scores by the GAD-7 categories. In both groups, the respondents with minimal anxiety had the lowest PSQI scores (7.2 \pm 2.9 for Saudis and $6.5 \pm 2.6$ for non-Saudis). In Saudis, those, with severe anxiety were found to have the highest PSQI score $(11.3 \pm 3.8)$ while in non-Saudis, the groups with moderate $(9.9 \pm 3.8)$ and severe $(9.7 \pm 3.4)$ anxiety both had higher scores as compared to the minimal anxiety group.

\section{Discussion}

The main purpose of the study was to determine an association between obesity levels, quality of sleep, and anxiety among the residents of Saudi Arabia including Saudis and non-Saudis. Saudi Arabia is among the nations with the highest prevalence of overweight and obesity. ${ }^{22}$ Our results are in concordance with the current literature as it showed a high proportion of overweight and obesity (32\%) and (29\%), respectively. There are many risk factors associated with the increased overweight and obesity levels in Saudi Arabia, including physical inactivity and a sedentary lifestyle. ${ }^{23}$ People's lifestyles have changed dramatically over the years, from active daily 
movement and proper dietary consumption to sedentary, inactive mobility and increased consumption of fat and sugar. ${ }^{24}$

Upon dividing the Saudi nationals from the non-Saudis, there was no significant difference between the frequency of exercise in both groups. Our findings revealed that the proportion of respondents who did not exercise frequently is more than half, which matches the literature regarding the low physical activity engagement in Saudi Arabia. ${ }^{25}$

Although obesity and anxiety are individually common and widespread health problems, more research has been linking them together. An 11-year cohort study found that both men and women experiencing anxiety and depression had a significantly higher incidence of obesity. ${ }^{26}$ Our results indicated a highly significant association between the BMI groups and the GAD-7 categories in Saudi nationals but not in the non-Saudi respondents. DeJesus et al. conducted a study with similar results to ours, indicating higher anxiety scores associated with very low and very high BMI levels in comparison to normal weight. ${ }^{27}$ Another research in Iran also supports that higher anxiety scores are associated with low weight. ${ }^{28}$ On the other hand, a study conducted among adults in 2016 showed higher anxiety scores for medium to high BMI levels and an inverted U-shaped association for both low and very high BMI levels with anxiety. ${ }^{29}$ For Saudis, it was found that almost half the 'Normal weight' group had the highest proportion of minimal anxiety as compared to about one-third in the obese group. The obese group was also found to have the highest proportion of mild and severe anxiety as compared to the other three BMI groups. However, the underweight group had the highest proportion of candidates with moderate anxiety.

On the other hand, while both Saudis and non-Saudis had a similar BMI distribution, a lack of relationship between BMI and anxiety levels in non-Saudis may imply that BMI might not be as relevant a risk to non-Saudis as it is to Saudis in developing anxiety. This could mean that other stressors and risk factors have a greater effect on non-Saudis. This difference could be genetic or environmental, but since no research has tackled the causes and risk factors for anxiety in non-Saudis as opposed to Saudis, any reasoning provided would be purely speculative.

Additionally, exercise is used to manage anxiety symptoms. ${ }^{30}$ Another study concluded that there is a positive association between anxiety and insufficient physical activity. ${ }^{31}$ This was demonstrated in our study in the non-Saudi population. Regarding obesity and quality of sleep, we found that the non-Saudi respondents who were obese or overweight had significantly higher PSQI scores as compared to the underweight group, which means poorer quality of sleep. A meta-analysis study $(n=164,016)$ suggests short sleep duration was significantly associated with the incidence of obesity. ${ }^{32}$ One of the studies concluded that additional wakefulness requires additional intake of food. However, due to the availability and easy access to food, the intake usually exceeded the requirement. ${ }^{33}$ Moreover, another study suggested that sleep deprivation even impacts the food choices one makes. Since sleep deprivation decreases the activity of the regions in the frontal cortex and the insular cortex responsible for the appetitive evaluation and increase the activity of the amygdala. These changes promoted the desire for high-calorie, obesity-inducing food. ${ }^{34} \mathrm{On}$ the other hand, obesity has been shown to decrease sleep duration and overall sleep quality since it is a major risk factor for obstructive sleep apnea (OSA). This can be seen as data suggests that OSA is almost twice as prevalent in obese patients as compared to normal weight. The reason for this could be due to the fat deposition in the upper airway and thorax, reducing the lumen and compliance of the airway. As BMI increases, further fat deposition is seen. With the decreasing lumen, the oxygen saturation decreases. ${ }^{35}$ One study also showed a significant association between mean oxygen saturation and sleep duration. ${ }^{36}$ In our study however, the Saudi sample did not reveal this association despite having a significantly higher mean PSQI score than non-Saudis, suggesting that other factors play a more important role in this poor quality of sleep seen in Saudis.

A cohort study exploring risk factors for developing Excessive Daytime Sleepiness EDS in 4,322 Sweden women over a 10 -year follow-up, $8 \%$ of them developed EDS, the incidence mostly being related to anxiety, obesity, and insomnia-among other factors. ${ }^{37}$ Another study found that sleep disturbances can lead to emotional dysregulation, which in turn leads to emotional eating, and thus to overweight and obesity. ${ }^{38}$

Similarly, in our study, the association between anxiety and sleep can be demonstrated in both the Saudi and the nonSaudi population. In both groups, the respondents with minimal anxiety had the lowest PSQI scores. In Saudis, those, with severe anxiety were found to have the highest PSQI score while in non-Saudis, the groups with moderate and severe anxiety both had higher scores. Another meta-analysis study concluded that sleep deprivation-induced states of increased anxiety, while sleep restriction did not show a significant relationship. Moreover, a longer period of sleep deprivation was a determinant of the increase in anxiety. ${ }^{39}$ A study among in Puerto Rican youth showed that sleeping less and having depressive/anxiety disorder were both independently and in combination associated with an increased risk of obesity. ${ }^{40}$

The cross-sectional nature of our study limits causal inferences. Also, since it was an online questionnaire, recall bias is one of the major limitations, especially in reporting height and weight, hence, BMI levels. However, this study shows significant findings among the residents of Saudi Arabia. There are limited studies that focus on obesity, sleep and anxiety.

In conclusion, there is a relation between the obesity, sleep, and anxiety trio, and a relation between the trio leading to other medical issues. Low and High BMI levels were significantly associated with moderate and severe anxiety. Also, overweight and obesity were associated with poor quality of sleep. Some studies claim that anxiety is the moderator between obesity and sleep, in which the presence of anxiety symptoms contributes to difficulty falling or staying asleep, which then increases the risk for obesity, or that poor sleep leads to anxiety, which leads to emotional eating and obesity. ${ }^{38}$ Obesity is a major problem in Saudi Arabia and must be given extreme attention from healthcare providers and policymakers to decrease its levels and prevent any negative consequences associated with it.

\section{Conflict of Interest}

The authors declare no conflict of interest.

\section{Funding}

This research did not receive any specific grant from funding agencies in the public, commercial, or not-for-profit sectors. 


\section{References}

1. Purnell JQ. Definitions, classification, and epidemiology of obesity. Endotext [Internet]: MDText. com, Inc.; 2018.

2. Djalalinia S, Qorbani M, Peykari N, Kelishadi R. Health impacts of obesity. Pakistan journal of medical sciences. 2015;31(1):239.

3. Casadei K, Kiel J. Anthropometric Measurement. StatPearls [Internet]: StatPearls Publishing; 2020

4. Arroyo-Johnson C, Mincey KD. Obesity epidemiology worldwide. Gastroenterology Clinics. 2016;45(4):571-9.

5. Al-Hussaini A, Bashir MS, Khormi M, AlTuraiki M, Alkhamis W, Alrajhi M, et al. Overweight and obesity among Saudi children and adolescents: Where do we stand today? Saudi journal of gastroenterology: official journal of the Saudi Gastroenterology Association. 2019;25(4):229.

6. Al-Ghamdi S, Shubair MM, Aldiab A, Al-Zahrani JM, Aldossari KK, Househ M, et al. Prevalence of overweight and obesity based on the body mass index; a cross-sectional study in Alkharj, Saudi Arabia. Lipids in health and disease. 2018;17(1):134.

7. Al-Hazzaa HM. Physical inactivity in Saudi Arabia revisited: A systematic review of inactivity prevalence and perceived barriers to active living. Int $J$ Health Sci (Qassim). 2018;12(6):50-64

8. Ahmed AE, Al-Jahdali F, AlAlwan A, Abuabat F, Bin Salih SA, Al-Harbi A, et al. Prevalence of sleep duration among Saudi adults. Saudi Med J. 2017;38(3):276-83

9. Buysse DJ. Sleep Health: Can We Define It? Does It Matter? Sleep. 2014:37(1):9-17.

10. Worley SL. The Extraordinary Importance of Sleep: The Detrimental Effects of Inadequate Sleep on Health and Public Safety Drive an Explosion of Sleep Research. P T. 2018;43(12):758-63.

11. Panel CC. Recommended Amount of Sleep for a Healthy Adult: A Joint Consensus Statement of the American Academy of Sleep Medicine and Sleep Research Society. Sleep. 2015;38(6):843-4.

12. Goel N, Basner M, Rao H, Dinges DF. Circadian rhythms, sleep deprivation, and human performance. Progress in molecular biology and translational science. 119: Elsevier; 2013. p. 155-90.

13. Landolt H-P, Holst SC, Sousek A, Bassetti C, Dogas Z, Peigneux P. Effects of acute and chronic sleep deprivation. 2014

14. Cooper CB, Neufeld EV, Dolezal BA, Martin JL. Sleep deprivation and obesity in adults: a brief narrative review. BMJ open sport \& exercise medicine. 2018;4(1)

15. Roberge $P$, Normand-Lauzière F, Raymond I, Luc M, Tanguay-Bernard M-M, Duhoux A, et al. Generalized anxiety disorder in primary care: mental health services use and treatment adequacy. BMC family practice. 2015;16(1):146.

16. Crocq M-A. The history of generalized anxiety disorder as a diagnostic category. Dialogues in clinical neuroscience. 2017;19(2):107.

17. Stein MB, Sareen J. Generalized anxiety disorder. New England Journal of Medicine. 2015;373(21):2059-68

18. Lykouras L, Michopoulos J. Anxiety disorders and obesity. Psychiatriki. 2011;22(4):307-13.

19. Sapra A, Bhandari P, Sharma S, Chanpura T, Lopp L. Using Generalized Anxiety Disorder-2 (GAD-2) and GAD-7 in a Primary Care Setting. Cureus. 2020;12(5).

20. Buysse DJ, Reynolds III CF, MonkTH, Berman SR, Kupfer DJ. The Pittsburgh Sleep Quality Index: a new instrument for psychiatric practice and research. Psychiatry research. 1989;28(2):193-213.

21. Weir CB, Jan A. BMI classification percentile and cut off points. 2019.
22. SS MA. A review of prevalence of obesity in Saudi Arabia. J Obes Eat Disord. 2016;2(2):25.

23. Alharbi C, Jackson R, editors. Physical Activity and the Prevalence of General and Abdominal Obesity among Saudi Women of Reproductive Age in Jeddah2017.

24. Algahtani FD. Healthy Lifestyle among Ha'il University Students, Saudi Arabia. Int J Pharm Res Allied sci. 2020;9(1):160-7.

25. Alahmed Z, Lobelo F. Physical activity promotion in Saudi Arabia: A critical role for clinicians and the health care system. Journal of epidemiology and global health. 2018;7:S7-S15.

26. Brumpton B, Langhammer A, Romundstad P, Chen Y, Mai X-M. The associations of anxiety and depression symptoms with weight change and incident obesity: The HUNT Study. International Journal of Obesity. 2013;37(9):1268-74

27. DeJesus RS, Breitkopf CR, Ebbert JO, Rutten LJF, Jacobson RM, Jacobson DJ, et al. Associations between anxiety disorder diagnoses and body mass index differ by age, sex and race: a population based study. Clinical practice and epidemiology in mental health: CP \& EMH. 2016;12:67.

28. Javadi M, Jourabchi Z, Shafikhani AA, Tajik E. Prevalence of depression and anxiety and their association with body mass index among high school students in Qazvin, Iran, 2013-2014. Electronic Physician. 2017;9(6):4655.

29. Haghighi M, Jahangard L, Ahmadpanah M, Bajoghli H, Holsboer-Trachsler $\mathrm{E}, \mathrm{Brand} \mathrm{S}$. The relation between anxiety and $\mathrm{BM}-$-is it all in our curves? Psychiatry research. 2016;235:49-54

30. Kandola A, Vancampfort D, Herring M, Rebar A, Hallgren M, Firth J, et al. Moving to Beat Anxiety: Epidemiology and Therapeutic Issues with Physical Activity for Anxiety. Curr Psychiatry Rep. 2018;20(8):63.

31. Wang H, Fu J, Lu Q, Tao F, Hao J. Physical activity, body mass index and mental health in Chinese adolescents: a population based study. The Journal of sports medicine and physical fitness. 2014;54(4):518.

32. Wu Y, Zhai L, Zhang D. Sleep duration and obesity among adults: a metaanalysis of prospective studies. Sleep medicine. 2014;15(12):1456-62.

33. Markwald RR, Melanson EL, Smith MR, Higgins J, Perreault L, Eckel RH, et al. Impact of insufficient sleep on total daily energy expenditure, food intake, and weight gain. Proceedings of the National Academy of Sciences. 2013;110(14):5695-700.

34. Greer SM, Goldstein AN, Walker MP. The impact of sleep deprivation on food desire in the human brain. Nature communications. 2013;4(1):1-7.

35. Romero-Corral A, Caples SM, Lopez-Jimenez F, Somers VK. Interactions between obesity and obstructive sleep apnea: implications for treatment. Chest. 2010;137(3):711-9.

36. Risso TT, Poyares D, Rizzi CF, Pulz C, Guilleminault C, Tufik S, et al. The impact of sleep duration in obstructive sleep apnea patients. Sleep and Breathing. 2013;17(2):837-43.

37. Theorell-Haglöw J, Åkerstedt T, Schwarz J, Lindberg E. Predictors for development of excessive daytime sleepiness in women: a populationbased 10-year follow-up. Sleep. 2015;38(12):1995-2003.

38. Nguyen-Rodriguez ST, McClain AD, Spruijt-Metz D. Anxiety mediates the relationship between sleep onset latency and emotional eating in minority children. Eating behaviors. 2010;11(4):297-300.

39. Pires GN, Bezerra AG, Tufik S, Andersen ML. Effects of acute sleep deprivation on state anxiety levels: a systematic review and meta-analysis. Sleep medicine. 2016;24:109-18

40. Koinis-Mitchell D, Rosario-Matos N, Ramírez RR, García P, Canino GJ, Ortega AN. Sleep, depressive/anxiety disorders, and obesity in Puerto Rican youth Journal of clinical psychology in medical settings. 2017;24(1):59-73.

This work is licensed under a Creative Commons Attribution-NonCommercial 3.0 Unported License which allows users to read, copy, distribute and make derivative works for non-commercial purposes from the material, as long as the author of the original work is cited properly. 